\title{
Responsabilidade solidária dos entes federativos pela obrigação de prestar serviço de saúde e vedação do chamamento ao processo: análise jurídica e econômica dos entendimentos do STF e STJ
}

Solidarity responsibility of federal entities for the obligation to provide health service and prohibition of the call to the process: legal and economic analysis of the understandings of STJ and STF

Responsabilidad solidaria de los entes federativos por la obligación de prestar servicio de salud y vedación de la llamada al proceso: análisis jurídico y económico de los entendimientos del STJ y STF

Lília Almeida $^{1}$

RESUMO: $O$ artigo aborda os atuais entendimentos jurisprudenciais sobre a responsabilidade dos entes federativos pelas prestações de serviços de saúde no Brasil e suas consequências processuais. Relaciona-se o Princípio da Solidariedade como fundamento do Federalismo Cooperativo e confronta-se seu significado com a obrigação solidária, categoria jurídica conceituada no Código Civil. Verifica-se as consequências materiais das decisões, conjugando-se o enfoque econômico ao critério de justiça, a fim de avaliar a necessidade de revisão dos entendimentos e adoção de providências legislativas, em busca da maximização de resultados.

Palavras-chave: Federalismo. Direito a Saúde. Poder Judiciário

ABSTRACT: This article deals with current jurisprudential understandings on the responsibility of federal entities for the provision of health services in Brazil and its procedural consequences. The Principle of Solidarity is related as the foundation of the Cooperative Federalism and its meaning is confronted with the solidarity obligation, legal category conceptualized in the Civil Code. The material consequences of the decisions are verified, combining the economic approach with the criterion of justice, in order to evaluate the need for revision of the understandings and adoption of legislative measures, in search of the maximization of results.

Keywords: Federalism. Right to Health. Judiciary

RESUMEN: El artículo aborda los actuales entendimientos jurisprudenciales sobre la responsabilidad de los entes federativos por las prestaciones de servicios de salud en Brasil y sus consecuencias procesales. Se relaciona el Principio de la Solidaridad como fundamento del Federalismo Cooperativo y se confronta su significado con la obligación solidaria, categoría jurídica conceptuada en el Código Civil. Se verifican las consecuencias materiales de las decisiones, conjugando el enfoque económico al criterio de justicia, a fin

\footnotetext{
${ }^{1}$ Mestranda em Gestão Pública no Instituto de Direito Público de Brasília. Especialista em Direito Processual Civil pela Universidade de Fortaleza. Procuradora do Distrito Federal. Brasília - Distrito Federal. Brasil. Email: liliaalmeida2014@gmail.com.br.
} 
de evaluar la necesidad de revisión de los entendimientos y adopción de providencias legislativas, en busca de la maximización de resultados.

Palabras-Ilave: Federalismo. Derecho a la Salud. Poder Judicial.

\section{Introdução}

A função primordial do Poder Judiciário é solucionar conflitos por meio da aplicação das normas jurídicas aos casos postos sob sua apreciação. A conclusão alcançada cria lei entre as partes do processo e, em alguns casos, tem efeito geral e vinculante. Por essa razão, é defensável que o Judiciário avalie as consequências concretas das decisões que prolata, também sob o enfoque econômico, que deve ser conjugado ao critério de justiça, para a construção da norma mais adequada.

Sobre as relações entre Direito e Economia, discorre Ricardo Villas Boas Cueva:

Nesse contexto, a análise econômica do direito, que ocupa, de acordo com Richard Posner, posição intermediária entre o positivismo jurídico e teorias de livre interpretação da constituição, como, por exemplo, a teoria da ponderação, pode ser particularmente útil, como uma espécie de consequencialismo mitigado, para orientar a elaboração de políticas públicas e a tomada de decisões, particularmente nos casos difíceis, nos quais seja exercida discricionariedade judicial.(1)

As decisões analisadas a seguir, além de partirem de premissas jurídicas equivocadas, primaram unicamente pelo critério de justiça, desconsiderando os inúmeros reflexos na organização e funcionamento do Sistema Único de Saúde (SUS).

A primeira decisão foi proferida no julgamento do Recurso Extraordinário n. 855.718RN. Nela, o Supremo Tribunal Federal (STF) reafirmou precedentes no sentido de que os entes federativos têm responsabilidade solidária ${ }^{2}$ pela prestação de serviços de saúde. Entendeu-se que o art. 23 da Constituição Federal, que insere a assistência à saúde no rol das competências comuns, é o fundamento da solidariedade entre as esferas de governo.

A segunda decisão foi proferida pelo Superior Tribunal de Justiça (STJ) no julgamento do Recurso Especial n. 1.203.244-SC. A despeito da jurisprudência segundo a qual os entes federativos têm responsabilidade solidária pela prestação de serviços saúde, essa

\footnotetext{
${ }^{2}$ Há solidariedade obrigacional quando na mesma obrigação existem mais de um credor ou devedor, cada um com direito, ou obrigado, à dívida toda. Assim, o credor pode cobrar a dívida integral de apenas um dos devedores solidários, que, por sua vez, poderá cobrar ressarcimento da cota parte dos demais devedores (art. 264, Código Civil). Segundo o art. 265 do CC, a solidariedade decorre da lei ou da vontade das partes, não podendo ser presumida.
} 
Corte Superior entendeu não ser possível o chamamento ao processo ${ }^{3}$ dos entes porventura não demandados.

É certo que há divisão de atribuições e custeio dos serviços de saúde entre todos os entes federativos. O termo único constante da denominação dada ao sistema apenas denota que não há diversos sistemas de saúde mantidos por cada um dos entes federativos; há, sim, um sistema integrado, mantido em colaboração. Não há superposição de atuação, pois, dentro do sistema, as responsabilidades de cada esfera são definidas a partir da lei e negociadas dentro da rede colaborativa, com base em algumas variáveis (como condições epidemiológicas, populacionais, etc.).

Há ações de saúde financiadas exclusivamente pela União, outras pelos estados, Distrito Federal e municípios ou rateadas entre todos ou alguns dos entes. A competência pela execução das ações de saúde também é dividida. A título de exemplo, cite-se a divisão de atribuições dentro da Assistência Farmacêutica (um dos blocos de atuação do SUS, que se refere ao fornecimento de remédios): ela é dividida em três componentes, o componente de Atenção Básica, o componente Especializado e o componente Estratégico. Dentro do componente Especializado, por exemplo, há os medicamentos para tratamento de doenças raras e de alta complexidade, cujo custo costuma ser muito elevado. Essas medicações são financiadas pela União - pois é o ente que possui mais condições de suportar essa despesa -, que em diversos casos adquire o fármaco e entrega aos demais entes para promoverem a dispensação (entrega ao paciente). Já o componente de Atenção Básica engloba medicações de custo mais baixo, voltadas a doenças mais comuns e corriqueiras, é financiado com recursos dos três entes, porém, a aquisição e dispensação é feita pelos gestores municipais, que estão mais próximos da população (2).

Nesse cenário, diante da complexidade de identificação do que cabe a cada ente, bem como pela dificuldade de acesso ao Judiciário em pequenas localidades do país ${ }^{4}$, passou-se a ajuizar ações em desfavor qualquer um dos entes federativos, com base no

\footnotetext{
${ }^{3}$ O Código de Processo Civil prevê essa forma de intervenção de terceiros no processo, com a finalidade de evitar o ajuizamento posterior de ação de cobrança contra os demais devedores solidários pelo devedor solidário que pagou a dívida integral sozinho. É medida de celeridade e economia processual e a lei garante sua utilização no caso de responsabilidade solidária (CPC, art. 130, III: É admissível o chamamento ao processo, requerido pelo réu - dos demais devedores solidários, quando o credor exigir de um ou de alguns o pagamento da dívida comum.)

${ }_{4}^{4}$ Demandas contra a União são de competência da Justiça Federal (art. 109, I, CF/88), assim, cidadãos residentes em cidades que não possuem vara federal têm maior dificuldade para demandar esse ente.
} 
argumento de que a competência pelo serviço de saúde é comum (art. 23, II, CF/88). Também se passou a defender que o chamamento ao processo (art. 130, III, Código de Processo Civil) não é admissível nesses casos, por atrasar a prestação jurisdicional.

O Judiciário pátrio, então, acolheu esses argumentos e fixou o entendimento de que todos os entes devem responder de forma solidária pelas prestações de serviço de saúde, independentemente da divisão de atribuições. Isso significa que o cidadão pode demandar a União, Estados e Municípios conjuntamente ou qualquer um deles individualmente pela prestação toda, conforme for de seu interesse.

O acerto da obrigação entre os entes das várias esferas de governo, contudo, não pode ocorrer no mesmo processo - como seria lógico, em razão da possibilidade de chamamento ao processo dos devedores solidários não demandados, como permite o sistema processual em vigor —, devido à decisão que veda essa intervenção de terceiros nas demandas de saúde.

Ocorre que, essas decisões, que são imbricadas, sob o fundamento de que se prestam a garantir o direito à saúde dos cidadãos, geram grande impacto na gestão do sistema, prejudicando sua racionalidade e retirando-Ihe eficiência funcional.

\section{Quadro normativo e conceitos essenciais à compreensão do tema}

Os precedentes jurisprudenciais acerca da responsabilidade solidária utilizam como principal fundamento o art. 23, II da CF/88, que diz: "Art. 23. É competência comum da União, dos Estados, do Distrito Federal e dos Municípios: Il - cuidar da saúde e assistência pública, da proteção e garantia das pessoas portadoras de deficiência"

Assim, é importante analisar no que consiste a solidariedade ligada ao art. 23, que estabelece as competências comuns dos entes federativos. Para tanto, faz-se necessária breve exposição sobre o surgimento do Federalismo Cooperativo e suas bases teóricas, porquanto é no contexto do Estado Federal que se estabelece a divisão de competências entre as esferas de poder. Assim, a interpretação do texto constitucional no que toca ao referido artigo, inclusive os contornos da solidariedade a ele atinente, não pode prescindir da análise de seus fundamentos, que estão ligados à teoria do Federalismo Cooperativo. 


\section{Do Federalismo Dual ao Federalismo Cooperativo}

A forma de Estado federativa teve como berço os Estados Unidos da América no final do Século XVIII. Por influência do Liberalismo, buscou-se evitar fortemente a intervenção do poder central na autonomia dos estados, pois a principal ideia dessa corrente é a preservação da liberdade dos cidadãos diante do Estado. Assim, transpondo-se essa ideia para a Federação, tinha-se por ser essencial a preservação da liberdade dos estados, como focos autônomos de poder. Para tanto, estabeleceu-se divisão estanque das competências de cada esfera de governo, caracterizando o chamado "federalismo dual".

Com as mudanças sociais e econômicas advindas da Revolução Industrial, surgiu uma classe de pessoas que não conseguia desenvolver autonomamente todas as suas potencialidades, devido à situação de hipossuficiência em que viviam. A fim contribuir para o equilíbrio nas relações sociais, a concepção acerca da atuação do Estado na economia migrou de uma visão eminentemente liberal e individualista para uma visão social e coletivista, permitindo a intervenção estatal na economia e sociedade. O Estado Liberal cedeu espaço ao Estado Social e, nesse contexto, as relações entre as esferas de poder no federalismo também foram influenciadas, detectando-se a necessidade de atuação uniforme dos entes federativos quanto aos problemas comuns, de forma cooperativa e coordenada, em busca do bem-estar social.

Essa transformação na concepção do federalismo, pautada pela cooperação entre os entes, ocorreu de forma semelhante em outras federações, como na Suíça e Alemanha, sendo observada também no Brasil, como se extrai das Constituições Federais de 1934, 1946 e 1988 (3). Segundo Bercovici (4), esses textos constitucionais adotaram o Federalismo Cooperativo como meio de alcançar o desenvolvimento uniforme dos entes federativos:

O Federalismo Cooperativo está em estreita relação com o Estado intervencionista (o chamado Estado Social), que tem por objetivos, entre outros, a igualação das condições sociais de vida e a redução das desigualdades socioeconômicas em todo o território nacional (no nosso caso, inclusive, por determinação expressa do art. $3^{\circ}$ da CF, conforme veremos adiante).

Percebe-se, assim, que a base teórico-filosófica dessa construção política é a vantagem social obtida por meio da cooperação e atuação solidária (solidária no sentido de interdependente e recíproca), como ensinado por Fábio Franco Pereira (5): 


\begin{abstract}
A federação, nesse sentido, é a reprodução, no plano político-jurídico, da idéia de vida em sociedade: a agregação de todas as forças dá ao todo que daí resulta aquilo que individualmente não se consegue. Segundo o conceito de mais-valia social, a sociedade vale mais que simples indivíduos sozinhos ou agrupados em mera soma aritmética. Por isso, que o mundo caminha cada vez mais para a socialização. A vida em sociedade permite alcançar feitos impossíveis quando se está sozinho. O mesmo se aplica à federação, que é, substancialmente, sociedade de Estados (...) Especialmente no federalismo cooperativo, típico do Estado social, intervencionista, a conjugação de esforços, que já é inerente à federação, deve ser acentuada, visando à redução das desigualdades sociais e, no caso brasileiro, por força do artigo $3^{\circ}$, III, da Constituição Federal, das desigualdades regionais.
\end{abstract}

\title{
Princípio da Solidariedade e Federalismo Cooperativo
}

A busca da igualdade requer atuação solidária (baseada em ajuda mútua) dos membros da sociedade; igualdade e solidariedade são princípios interrelacionados, que têm origem histórica remota, derivados de sentimentos humanos fundantes de regras de convivência e religiosas em diversas sociedades. Por influência desses preceitos, arraigados à cultura ocidental, o legislador pátrio positivou ambos os princípios-irmãos na Constituição Federal. O Princípio da Solidariedade é extraído de inúmeros dispositivos, mas está expresso no art. 3ํ, I da Carta Magna.

A busca pela redução das desigualdades regionais, objetivo maior do Federalismo Cooperativo, é, portanto, manifetação desse princípio, que preconiza ajuda mútua e atuação conjunta dos membros da comunidade. Como exposto, a base teórico-filosófica do Federalismo Cooperativo é a vantagem social da cooperação: passa-se de uma atuação essencialmente individualista, na qual as chances de desenvolvimento uniforme são mais reduzidas, para uma atuação pautada pela solidariedade, na qual a ajuda recíproca permite maior desenvolvimento e redução de desigualdades regionais (o que favorece à coesão e manutenção da união).

Nesse contexto, a solidariedade exsurge como elemento principiológico orientador dessa forma de organização política, como ensinado de forma elucidar por Ângela Maria Rocha Gonçalves Abrantes (6):

O Princípio da Solidariedade (também conhecido como princípio da Integração ou Princípio da Solidariedade Comunitária) implica em dever recíproco, em cooperação, em lealdade, em ajuda mútua, em coesão entre os Estados, tudo em prol do desenvolvimento igualitário entre Estados, regiões e Comunidades de Estados. (...) 
João Mota Campos justifica que o Princípio da Solidariedade é importante para a União Européia, por exemplo, porque ampara procedimentos que visam ao 'reforço da sua coesão econômica e social', através, designadamente, da redução da diferença entre as diversas regiões. Menciona, ainda, o jurista português que - com referência à União Européia - em nome deste princípio, 'os Estados mais ricos da Comunidade exprimem a sua solidariedade em relação aos menos desenvolvidos, consentindo, através de sua contribuição para o orçamento comunitário e portanto do financiamento das despesas comuns, numa transferência de recursos financeiros que implica o correspondente sacrifício próprio. Estão, pois, os Estados-membros ditos desenvolvidos obrigados pela solidariedade a criarem e utilizarem mecanismos de auxílio aos demais membros da União Européia. Compreende-se, consequentemente, que pelo Princípio da Solidariedade os Estados ditos mais ricos ou tecnologicamente desenvolvidos em certas áreas devem (em nome da colaboração e do equilíbrio da União, da integração e coesão dos Estados) 'partilhar' seus avanços e riquezas.

No mesmo sentido, abordando a repartição de competências no federalismo cooperativo brasileiro, Bercovici, em clássico artigo sobre o tema, explica que o princípio da solidariedade é que fundamenta a transferência considerável de recursos públicos entre as regiões (7). Em outro estudo, sobre relações entre a Constituição e o desenvolvimento, o mesmo autor enfatiza a importânica da repartição solidária de rendas como forma de concretização da cooperação na Federação (8):

A autonomia dos entes federados perante a União pode se transformar em farsa quando faltam os recursos financeiros necessários à sua manutenção. Consequentemente, num Estado Federal, a decorrência direta da repartição de competências é a distribuição das fontes de recursos financeiros para equilibrar os encargos e as rendas das unidades federadas. Além da discriminação rígida e tradicional das rendas por fontes, o Federalismo Cooperativo caracteriza-se por realizar a distribuição da receita pelo produto arrecadado, ou seja, a participação de entes federativos na receita de outros entes. (...) No tocante à destinação de verbas para a diminuição dos desequilíbrios regionais, a técnica utilizada na Constituição de 1988 é a da participação por expectativa ou participação em fundos.

Depreende-se, portanto, que a solidariedade atinente ao Federalismo Cooperativo, cujos expoentes na CF/88 são os arts. 23 e 24, relaciona-se à lealdade federativa e refere-se à necessidade de atuação conjunta e integrada dos entes federados, em busca da redução das desigualdades regionais (art. 3ำ I e III, CF/88). É concretizado pelo mecanismo de repartição de rendas, justificando a participação de entes federativos na receita de outros entes, em busca do desenvolvimento nacional. 


\section{Princípio da Solidariedade entre os entes federativos versus solidariedade obrigacional prevista no Código Civil Brasileiro}

"Obrigação" é o vínculo de direito pelo qual somos constrangidos à necessidade de pagar alguma coisa a alguém. Nos dizeres de Agerson Tabosa, "Seu relacionamento com as pessoas, com as coisas, com a família, com o comércio, com os crimes, com as sucessão, leva as obrigações a ocupar posição ímpar no ordenamento jurídico dos povos"(9). Por seu caráter geral, os conceitos construídos ao longo dos tempos pelo Direito das Obrigações podem ser considerados categorias jurídicas ${ }^{5}$, a partir das quais os vários ramos do direito vão acrescetando as características que lhe são próprias(10).

O conceito de obrigação solidária é um conceito eminentemente técnico, que decorre de criação ficcional do direito, não existindo como decorrência lógica de determinada relação jurídica. A solidariedade obrigacional ocorre quando há pluralidade de sujeitos na relação e seu objeto pode ser exigido/pago integralmente de/a qualquer um dos sujeitos (Art. 264, CC).

Sua aplicação nas relações jurídicas, seja por acordo seja por força de lei, tem fundamento na necessidade/ intenção de dar maior segurança à relação ${ }^{6}$.Por essa razão, a solidariedade é exceção, não se presume, deve estar expressa em lei ou acordo, como exposto por Clóvis Beviláqua (11):

A solidariedade é de exceção, se não deve jamais presumir, nem passará aos herdeiros do credor ou do devedor. Deve ser expressamente constituída por um dos fundamentos seguintes: um contrato, um testamento ou a determinação da lei

Comparando-se os dois conceitos analisados, vê-se que, apesar da semelhança de nomenclatura, não há equivalência entre a solidariedade norteadora da atuação dos

\footnotetext{
5 "Categoria jurídica é a formulação genérica, in abstracto, com índices essenciais, mas gerais, não comprometida ainda com nenhum dos ramos do direito. Trata-se da figura iuris tomada em sua generalidade máxima, caracterizada por conotações típicas do gênero, mas não identificadoras da espécie." (Reflexos do Direito Civil no Direito Administrativo. José Cretella, Revista da Procuradoria Geral do Estado de São Paulo, São Paulo, Junho de 1977).

6 "Pode-se aduzir que, das obrigações tratadas sob a perspectiva do critério da pluralidade de sujeitos, as solidárias possuem uma função econômico-social relevante, pois, embora haja apenas uma prestação, como sustenta P. BONFANTE, existe um traço característico nestas obrigações, que muito se aproxima daquilo que os modernos denominam garantia: 'a responsabilidade e a representação de um por todos'." (Martin, FB. Das obrigações solidárias: relação com as obrigações indivisíveis no sistema jurídico romano e refloxos no direito brasileiro. [Dissertação]. São Paulo: Universidade de São Paulo; 2015; pág. 35.
} 
entes federativos no exercício das competências comuns - princípio ligado à leadade federativa, indicador da necessidade de atuação conjunta e fundamentador da divisão de rendas - e a solidariedade obrigacional - categoria jurídica de cunho eminentemente técnico, aplicável aos casos em que o legislador expressamente assim o estabeleceu.

\section{Competências comuns - art. 23 da Constituição Federal, e solidariedade obrigacional - art. 264, Código Civil}

Sobre 0 art. 23 da Constituição Federal, Uadi Lammêgo Bulos comenta que "a competência comum é aquela conferida simultaneamente às entidades políticoadministrativas. Significa que devem cooperar na execução de tarefas e objetivos que the são correlatos".(12)

O autor faz coro com a crítica de Oswaldo Aranha Bandeira de Mello, no sentido de que a expressão "competência comum" não é das melhores, pois gera confusões e equívocos. Com efeito, a terminlogia leva o intérprete a pensar que se a competência é comum, cada um dos três entes poderia atuar independentemente dos demais nas áreas inseridas no rol. Apesar de não haver vedação explícita a isso, não é essa a vontade do legislador constituinte, que elegeu 0 art. 23 como um expoente do Federalismo Cooperativo, sendo essencial que todas as esferas de governo atuem conjuntamente de forma planejada.

Nesse contexto, a competência comum conclama a convocação de todas as pessoas políticas, para, numa combinação de esforços, concretizar suas responsabilidades recíprocas ${ }^{7}$. Assim, análise sistemática e teleológica do dispositivo, bem como o estudo das bases teóricas do Federealismo Cooperativo, indicam que uma atuação não colaborativa, assistemática e desintegrada dos entes federativos na criação e execução de políticas públicas ligadas ao rol das competências comuns não deve ser incentivada pelo legislador ordinário, menos ainda pelo Poder Judiciário, que não é formulador de políticas públicas.

\footnotetext{
${ }^{7}$ A legislação de regência prevê que a União, os estados, o Distrito Federal e os municípios devem pactuar as suas responsabilidades em relação ao financiamento e execução das ações e dos serviços de saúde (Decreto n. 7.508/11, arts. 30 e seguintes). Essa pactuação ocorre em grande parte no âmbito de comissões formadas por gestores representantes de cada esfera de governo. As principais são as Comissões Intergestores Bipartites, formadas por estados e municípios, e a Comissão Intergestores Tripartite, formada pela União, estados e municípios.
} 
Possivelmente por imprimir leitura rápida do texto constitucional, desatenta à semântica da solidariedade positivada no texto magno e aos objetivos das competências comuns, há quem defenda que do art. 23 da Constituição Federal decorre a solidariedade obrigacional dos entes federativos em relação aos cidadãos pelos serviços de saúde. Esse foi o entendimento seguido pelo STF no RE n. 855.178-RN.

Contudo, tal premissa é equivocada, como analisado acima: o Princípio da Solidariedade ligado ao art. 23 não se confunde com as categorias jurídicas eminentemente técnicas denominadas obrigação solidária/ responsabilidade solidária. Assim, esse dispositivo não atrai a aplicação do art. 264 do Código Civil, sendo equivocado o entendimento segundo o qual todos os entes federativos podem ser demandados indistintamente, ao talante do cidadão, independentemente das respectivas atribuições no SUS.

Pelos mesmos motivos, não há razão jurídica para se admitir que a solidariedade obrigacional, no sentido de possibilidade de cobrança da prestação a qualquer um dos devedores à escolha do credor, deflui diretamente do texto constitucional.

Não se trata, portanto, de interpretar a Constituição à luz da legislação ordinária. A solidariedade positivada nos arts. 3ำ, I; 23 e 196 da Constituição Federal, dentre outros, simplesmente tem conteúdo jurídico diverso e não se relaciona com a solidariedade positivada no art. 264 do Código Civil.

A solidariedade extraída do art. 23 existe entre os entes federativos reciprocamente considerados, significando que devem atuar em colaboração, como decorrência do Princípio da Solidariedade (art. 3ำ, I, CF/88). Não determina, assim, vínculo obrigacional solidário na acepção técnica que lhe empresta o legislador no art. 264, CC, em relação aos cidadãos que demandam prestações de saúde.

Ademais, a previsão de competência comum aponta para a atuação conjunta de todos os entes, mas não indica irrelevância de identificação das atribuições de cada um, dentro dos acordos de cooperação. Ao contrário, a divisão e identificação das atribuições de cada ente é essencial para evitar sobreposição de atuações, ou seja, diversas entidades executando as mesmas ações e, por isso, gerando ineficiência e desperdício de recursos.

Sobre a importância de respeito à divisão de atribuições administrativas no âmbito do SUS, discorre Álvaro Luís Ciarlini (13): 
Ora, o modelo administrativo em curso no Sistema Único de Saúde, quanto à distribuição dos ônus e responsabilidades a cada um dos entes federados, deve ser observado com especial atenção. Em verdade, a dinâmica ora exposta sinaliza para o fato de que a atribuição de caráter de solidariedade às eventuais obrigações impostas ao sistema deve ser analisada com merecida acuidade, pois, nesse caso, a intervenção do Poder Judiciário, mesmo que embasada no argumento de defesa de um específico direito fundamental, contraria o fundamento central do nosso sistema federativo "de cooperação", justamente na sua natureza descentralizada e autônoma, mas coordenada e legitimamente justificada pelo imperativo de obtenção da máxima eficácia dos seus meios.

\section{Vedação do chamamento ao processo nas demandas de saúde}

A despeito do entendimento adotado pelo Judiciário sobre responsabilidade solidária pela prestação dos serviços de saúde, vedou-se o chamamento ao processo da(s) entidade(s) não demandas. O fundamento da decisão proferida no Resp n. 1.203.244-SC baseia-se:

a) em aplicação direta da Constituição Federal (Princípio da dignidade da pessoa humana), sob o argumento de que a intervenção de terceiros atrasaria a prestação jurisdicional, sendo um meio protelatório para se evitar a prestação obrigacional;

b) no argumento de que o chamamento ao processo gera formação de litisconsórcio passivo facultativo, não sendo passível de interpretação extensiva para alcançar prestação de entregar coisa certa;

c) em precedente do STF (RE n. $607.381 \mathrm{AgR} / \mathrm{SC}$ ), segundo o qual não há utilidade do chamamento ao processo por não ser viável o direito de regresso ${ }^{8}$ e baseado em opinião doutrinária já revista, segundo a qual o chamamento ao processo enfraqueceria o direito de crédito (Nelson Nery Jr., em Comentários ao Código de Processo Civil, 10 edição).

Também nesses julgados, preocupado em resguardar o direito à saúde dos cidadãos, o Judiciário pátrio partiu de premissas equivocadas, como se passa a demonstrar:

a) quanto ao atraso na prestação jurisdicional, o STJ desconsiderou os meios de solução do problema previstos na própria legislação processual, consistente na garantia de

\footnotetext{
8 "Contudo, in casu, não há se falar em direito de regresso, pois, mesmo que a União integre o feito em comunhão com o Estado, caso saiam perdedores na demanda, o Estado de Santa Catarina arcará sozinho com o ônus do fornecimento do medicamento requerido, pois essa foi a opção da autora na ação." (RE 607.381 AgR/SC)
} 
entrega do bem da vida pleiteado ainda no início do processo, em caso de impossibilidade de esperar-se seu fim (art. 300, CPC - tutela de urgência);

b) o chamamento ao processo não gera ampliação subjetiva da ação (formação de litisconsórcio passivo), pois isso representaria violação ao direito do autor de optar contra quem quer litigar, assim, o melhor entendimento é que o chamamento amplia objetivamente a lide, com a criação de lide secundária entre réu e codevedores. Ademais, a lei não veda essa intervenção de terceiros quando o objeto da obrigação seja coisa certa, como faz crer o julgado. A lei civil e a lei processual civil referem-se a "dívida comum", sem qualquer limitação sobre o tipo de prestação obrigacional;

c) o argumento de não ser possível ação de regresso do ente demandado em face dos demais codevedores não se sustenta, pois, o fornecimento de prestação de saúde (medicamento, materiais, cirurgias etc.) tem custo pecuniário, que pode ser cobrado do ente responsável pela prestação no âmbito do SUS. Sobre o prejuízo ao credor causado pelo chamamento ao processo, defendido por Nelson Nery Jr. e utilizado como fundamento da decisão proferida pelo STF no RE 607.381/SC, entende-se revisto pelo processualista, que na atualização mais recente de sua obra consigna que o direito de crédito é beneficiado pela intervenção, pois o codevedor pode adimplir a prestação diretamente ao autor, facilitando o direito de crédito. (14)

\section{Análise econômica dos entedimentos}

\section{Incentivos ao bem-estar social}

Em relação aos cidadãos usuários dos serviços de saúde e também judiciários, argumenta-se que têm os seguintes benefícios:

a) A fundamentação dos pedidos formulados nas ações é feita unicamente com base nos normativos abstratos que tratam do direito à saúde, mais especificamente o art. $196 \mathrm{e}$ seguintes da CF/88. Não se exige maior esforço do autor em demonstrar a forma como o serviço está regulamentado no âmbito do SUS, menos ainda a quem compete a obrigação;

b) nos casos em que a União seja a responsável pelo custeio da ação de saúde, mas não haja seção da Justiça Federal na localidade, o autor não precisará arcar com os 
custos de ajuizamento da ação em outro local onde exista vara federal, pois pode optar por demandar apenas o estado e/ou município;

c) o cidadão pode optar por pleitear o serviço do ente que possuir mais recursos orçamentários.

\section{Prejuízos à eficiência e alocação de recursos}

Em decorrência dos entendimentos, permite-se que ocorra o custeio/execução de serviço de saúde por ente diverso do que detém a obrigação no âmbito do SUS e consequentemente orçamento/ estrutura para tanto.

Há diversos casos em que os estados membros, os municípios e o Distrito Federal vêm arcando com despesas para as quais não detêm recursos orçamentários ou estrutura para execução do serviço. O mesmo ocorre com a União, que tem sido condenada a arcar com despesas que deveriam ser custeadas pelos demais entes ou a prestar serviços sem que tenha estrutura para tanto.

Assim, a Administração Pública acaba fazendo uso de recursos que poderiam ser utilizados em outras ações/programas, para fazer frente à despesa de saúde que já está a cargo de outro(s) ente(s) federativo(s). Isso desestabiliza não só todo o sistema de financiamento estruturado para o SUS, mas também o orçamento dos entes federativos como um todo.

Sobre esse impacto deslocativo no orçamento público, explica o Conselheiro do Tribunal de Contas de Minas Gerais, Sebastião Helvécio Ramos:

Um provimento jurisdicional que ordene o atendimento público de determinada necessidade médica fora do estabelecido pelas normas e regulamentos do Sistema Único de Saúde (SUS) ou à revelia das políticas públicas traçadas dentro das limitações orçamentárias do Poder Público age em desfavor de toda a coletividade, pois atende a uma necessidade individual em detrimento do equilíbrio financeiro do sistema e subverte, portanto, os próprios direitos fundamentais, que, a princípio, pretendeu garantir.(15)

Some-se a isso o fato de que a compensação administrativa dessas despesas vem se mostrando difícil e com frequência inalcançável, ensejando possibilidade de conflito federativo e desestímulo à cooperação, imprescindível no âmbito do SUS e ao desenvolvimento econômico. Os gestores divergem entre si quando se trata de proceder a 
eventuais compensações, pois: a) a legislação não prevê como deve ser feito esse ressarcimento; b) como o chamamento ao processo é vedado pela jurisprudência firmada, não se forma título executivo contra os demais entes, assim, não há sanção para a recursa a pedido de ressarcimento/ compensação administrativa, o que desestimula o pagamento voluntário.

Isso pode ensejar o ajuizamento de ações de cobrança entre entes da federação, para obter o ressarcimento dos valores nos termos definidos pelo pacto interfederativo. Cite-se como exemplo a ação recentemente ajuizada pelo Estado de Pernambuco contra a União, para cobrança de quase um bilhão de reais (Processo n. 080581485.2015.4.05.8300), a qual a Justiça Federal de Pernambuco remeteu ao STF, por vislumbrar potencial desestabilização do pacto federativo.

Além dos problemas relativos à alocação de recursos, as decisões provocam desorganização no funcionamento dos serviços, o que gera perda de eficiência, como se constata pelos seguintes exemplos concretos:

a) Impossibilidade de verificação da prescrição médica pela União, que não tem como controlar a veracidade/ adequação do tratamento. A União não possui estrutura atendimento farmacêutico direto aos cidadãos, pois via de regra não executa serviços de saúde (Lei 8.080/90). Assim, não há como manter controle do receituário atualizado, o que dá margem a fraudes. Outro inconveniente é que a União não tem postos de entrega de medicamentos, o que acaba gerando gastos extras com a entrega da medicação no domicílio dos autores. Devido também a essa circunstância, há notícias de quem opte por ajuizar a ação contra a União, em razão dessa "comodidade"(16);

b) quando um ente é condenado a fornecer uma medicação que não pertence ao elenco atribuído a si, obviamente não possui estoque. A aquisição da medicação deve ser efetuada de forma a não haver a interrupção do tratamento; assim, como cada procedimento de compra dura de 2 a 3 meses, as compras são feitas para um período em média de 6 meses de tratamento. Se nesse período houver óbito do paciente, alteração da medicação ou cura, o produto adquirido não será mais útil ao ente comprador, que possivelmente perderá o recurso investido;

c) quando o ente não tem atribuição de fornecer certo produto, o procedimento de compra para atender a decisão judicial será menos vantajoso, pois aquisição em quantidades pequenas diminuem a possibilidade de obtenção de menores preços; 
d) a máquina administrativa se mobiliza para cumprir obrigação que não é sua, nos termos dos pactos interfederativos, e sequer tem estrutura para tanto, deixando de dar andamento mais eficiente às atribuições que efetivamente lhe são pertinentes;

e) as defesas judiciais são apresentadas sem que sequer tenha-se acesso aos fatos ou elementos técnicos relacionados ao caso, pois a prestação do serviço é incumbência de outra entidade, com franco prejuízo à ampla defesa (p. ex. o paciente se encontra internado em hospital estadual e pede cirurgia para a União; o médico prescritor da medicação faz parte da rede pública estadual, mas pede-se o fármaco à União, que não tem acesso sequer ao prontuário médico do paciente). Isso também prejudica a eficiência administrativa;

f) incentiva-se o ajuizamento de várias ações pelo mesmo autor em face de diferentes estados ou municípios e União, gerando prejuízo à ampla defesa e abrindo caminho a fraudes ${ }^{9}$.

\section{Comparação entre os benefícios e prejuízos decorrentes dos entendimentos jurisprudenciais}

A questão que se põe é: o aumento da facilidade de acesso ao Judiciário e a serviço individual de saúde justificam os problemas gerados à organização do sistema, com evidente perda de eficiência, assim como os prejuízos financeiros que daí também advêm?

Da análise comparativa entre os benefícios oriundos das decisões e os custos impostos por elas, conclui-se que não ${ }^{10}$. É evidente a ocorrência de desperdício de recursos públicos e prejuízo à eficiência do sistema, como demonstrado nos exemplos

\footnotetext{
9 "O ajuizamento indistintamente de ações contra um, alguns ou todas as três esferas governamentais tem contribuído para dificultar a operacionalização da universalidade e igualdade no SUS, pois os entes são demandados isoladamente, em Justiças diferentes, não havendo comunicação processual aos demais entes não constantes da lide, impossibilitando, muitas vezes, a identificação de litispendência, coisa julgada, e mesmo reconhecimento do pedido, já que tem ocorrido de o autor demandar um ente, quando o outro ente federado está prestando regularmente o serviço ou medicamento pleiteado." (Bezerra, FLO. Imbricações entre competência de jurisdição, legitimidade e solidariedade na tutela da saúde pública. Revista Dialética de Direito Processual. N. 81, p. 27-34, dez., 2009, pág. 33)

${ }^{10}$ Segundo Fernando Meneguin: "Sabe-se que a sociedade deve fazer escolhas. Para tanto, realiza-se a análise custo-benefício para se comparar a diferença positiva entre os benefícios globais (econômicos e sociais) e os custos globais de cada opção. Podem-se utilizar conceitos econômicos e, por analogia, enunciar o seguinte: uma lei é dita eficiente se os benefícios oriundos da norma compensam os custos impostos por ela, além de esses custos serem os menores possíveis. Esse é o conceito que será utilizado a seguir, focando no fato de que a norma jurídica e as decisões judiciais, aos buscarem eficiência, devem procurar propiciar uma estrutura de incentivos adequada de forma a não acarretar desperdícios de recursos". Disponível em: http://www.brasil-economia-governo.org.br/wp-content/uploads/2013/09/as-leis-podematrapalhar-a-eficiencia.pdf. [Acesso em 30.abr.2018].
} 
dados nos itens precedentes. Por outro lado, o ganho de facilidade no ajuizamento das demandas pelo usuário não compensa os prejuízos sofridos pelo sistema e consequentemente por toda a coletividade.

Nesse contexto, verifica-se que o custo marginal social é maior que o custo marginal privado do cidadão que litiga contra o Estado, pois os benefícios oriundos das decisões não compensam os custos impostos por elas.

Mesmo para os cidadãos que precisam demandar o Estado num momento de vulnerabilidade e beneficiam-se da facilidade derivada das decisões analisadas, a resposta negativa. É negativa, pois esses cidadãos, mesmo depois de obterem o serviço específico judicialmente, continuarão a necessitar de outros serviços de saúde. Assim, a potencial derrocada do sistema prejudicará inclusive aos usuários que, em algum momento, beneficiaram-se dessas decisões.

Essa circunstância não costuma ser ponderada por quem defende o acerto das decisões em comento porque o benefício individual no momento em que se demanda o Estado é palpável e concreto; enquanto o prejuízo decorrente da desestabilização do sistema é pulverizado, impalpável, eventual. Isso faz com que a escolha individual não leve em consideração o que seria a melhor escolha social. Aplica-se claramente a observação da Economia Comportamental segundo a qual benefícios presentes são mais valorizados que os benefícios futuros.

Some-se a isso o fato de essas decisões fomentarem conflitos em vez de incentivar a cooperação entre os entes federativos, o que, sob o prisma do desenvolvimento econômico é inaceitável. Segundo Ronaldo Fiani, o sucesso das instituições na promoção do desenvolvimento "depende da medida em que elas conseguem oferecer possibilidades de solução para os conflitos e incentivar a cooperação, sem que o desenvolvimento enfrente grandes obstáculos"(17). No âmbito do SUS, essa cooperação é essencial, conforme exposto acima, e sem ela o sistema perde sua funcionalidade.

Por essas razões, os entendimentos das decisões precisam ser revistos, de forma a maximizarem-se os resultados, ou seja, de forma a optar-se pela melhor alternativa, consideradas as restrições existentes.

Assim, considerando os benefícios citados, bem como os prejuízos até então detectados, sugerem-se as seguintes alternativas para a maximização dos resultados: 


\section{Revisão do entendimento firmado no RE $\mathrm{n}$. 855.178-RN - respeito à organização administrativa do SUS e à regra de competência prevista no art. 109, I da CF/88}

A opção que efetivamente proporcionaria a maximização dos benefícios e minoração de custos, tanto para os administrados em uma perspectiva coletiva quanto para os administradores, seria reformular completamente 0 entendimento, respeitando-se a organização administrativa do sistema.

Anote-se que, sob o aspecto jurídico, a revisão do entendimento é viável, pelas razões indicadas em linhas pretéritas, pois partiu de premissa equivocada, qual seja, a identidade entre a solidariedade relacionada ao art. 23 da Constituição Federal e a obrigação solidária conceituada no art. 264 do Código Civil.

Além disso, é importante atentar que o posicionamento atual viola a regra do art. 109, I da CF/88, pois se houver, no caso concreto, interesse da União, a solidariedade obrigacional não pode ter o condão de afastar a competência absoluta da Justiça Federal. (18)

Sobre os óbices normalmente levantados contra a revisão do entendimento, tem-se que não se sustentam. Quanto à dificuldade de identificação das atribuições no emaranhado de normas administrativas, há possibilidade de especialização de varas, para melhor apreensão dos normativos pelos magistrados, e de compilação da legislação do SUS por meio de atuação colaborativa dos atores envolvidos. Ademais, a grande maioria dos casos, senão em todos os casos, o cidadão é representado ou pelas Defensorias Públicas ou por advogados privados, profissionais habilitados e capazes de conhecer os normativos do SUS se assim for exigido ${ }^{11}$.

No tocante ao intuito de evitar o deslocamento de pacientes para localidades munidas de varas federais, no caso de precisarem demandar a União, pode haver criação legislativa autorizando o exercício de competência federal por juízes estaduais, assim como ocorre com as demandas previdenciárias (art. 109, §3ํㅡ, CF/88).

\footnotetext{
11 "A inexistência de uma consolidação das normas do SUS dificulta sobremaneira a compreensão do sistema. Contudo, a falta de clareza normativa para orientar o usuário sobre o órgão responsável para prestar o serviço de saúde não justifica que operador do direito se acomode, furtando-se do dever de analisar as normas administrativas distributiva de responsabilidade, optando pelo que poderia ser intitulando de 'solidariedade preguiçosa'." (Dresh Renato. In: SANTOS, Lenir; TERRAZ, Fernanda (Org.). Judicialização da Saúde no Brasil. Campinas: Saberes, 2014. p. 25-57).
} 
Essas providências - criação de varas especializadas, compilação e divulgação das normas de organização do SUS e previsão de competência federal aos juízes estaduais para processar ações de saúde - podem ser classificadas como o custo de oportunidade $^{12}$ da alteração dos entendimentos judiciais reafirmados nas decisões sob análise.

O caminho a ser trilhado em direção à garantia do acesso à Justiça é a estruturação do Judiciário e das instituições essenciais à Justiça, de forma a atenderem adequadamente os cidadãos. Não se justifica, jurídica ou economicamente, que para facilitar o acesso à Justiça se desrespeitem normas administrativas de organização do SUS, com franco prejuízo financeiro e à eficiência. Assim, o custo de oportunidade nesse caso (investimento no Judiciário e instituições essenciais à Justiça) não seria excepcional, pois inferior ao prejuízo sofrido pelo sistema de saúde, conforme ilustrado nos exemplos anteriormente citados.

\section{Edição de norma constitucional estabelecendo de forma explícita que a responsabilidade por prestações decorrentes da competência comum deve ser exigida de acordo com as atribuições de cada ente federativo e responsabilidade conjunta no caso de omissão de política pública}

Caso o Judiciário pátrio insista em manter os entendimentos firmados, a despeito da superficialidade de seus fundamentos e equívoco de premissas, vislumbra-se a possibilidade de edição de norma constitucional explicitando que a responsabilização de cada ente federativo no campo das competências comuns deve observar suas atribuições administrativas específicas. Entende-se que a lei indicada no parágrafo único do art. 23 não seria conveniente para concretizar tal providência, pois passível de declaração de inconstitucionalidade, porquanto o entendimento judicial considera que a solidariedade obrigacional deflui diretamente do texto constitucional.

A norma editada pelo legislador constituinte derivado deve prever também que há responsabilidade conjunta na hipótese de omissão de política pública. Não se pode olvidar o escopo do legislador constituinte, ao instituir o Federalismo Cooperativo: as obrigações comuns de cada esfera de governo devem ser definidas mediante pactuação, de forma

\footnotetext{
${ }^{12}$ Conceito essencial à Economia, significa o quanto temos que abrir não de algo, para conseguir mais de outro item mais importante.
} 
colaborativa. Assim, o correto, sob o prisma não só econômico, mas também, jurídico, seria o cidadão demandar, em caso de omissão, as três esferas de governo - e não apenas uma ou uma delas a seu talante - para que, em conjunto, cooperativamente como deseja o constituinte, definam como se cumprirá a obrigação e possam, a partir daí, estabelecer a política pública faltante.

Uma atuação não colaborativa, assistemática e desintegrada dos entes federativos na criação e execução de políticas públicas ligadas ao rol das competências comuns não pode ser admitida, pois, no Brasil, o desiderato do legislador constituinte originário não tem sido alcançado, dentre outros motivos, justamente pela falta de coordenação entre as diversas esferas de governo, como conclui Fábio Franco Pereira:

(...) no tocante às competências materiais comuns, o constituinte e, posteriormente, o legislador ordinário, promoveram a descentralização de forma incorreta, sem planejamento adequado e negociado com Estados e Municípios, sem a coordenação típica do federalismo cooperativo, o que contribuiu decisivamente para a desordem e a dispersão de esforços na prestação de serviços públicos essenciais.(19)

\section{Revisão do entendimento relativo à vedação do chamamento ao processo}

Terceira opção, viável caso não se admita a inexistência de solidariedade obrigacional na acepção técnica que Ihe dá o art. 264 do Código Civil, seria permitir o chamamento ao processo dos demais entes não demandados. Isso proporciona a possibilidade de o ente com estrutura e orçamento para prestar o serviço, prestá-lo, evitando desperdício de eficiência e recursos. Facilita, também, o acerto da responsabilidade entre os entes e evita o ajuizamento de outra ação, com possível deflagração de conflito federativo.

O alegado prejuízo à celeridade do processo não se confirma na prática, pois havendo necessidade imediata do tratamento, esse é fornecido com base em decisão de urgência. Atualmente, há inúmeros processos cujo objeto é prestação de serviços de saúde, que se arrastam há anos no Judiciário sem prejuízo aos autores, pois, demonstrada a necessidade imediata do tratamento, esse é fornecido com base em liminares.

Por outro lado, o chamamento ao processo é medida de economia processual, que evita o posterior ajuizamento de ação de regresso contra os codevedores, sendo medida importante para a redução da quantidade de ações que tramitam no Judiciário pátrio, atualmente na casa dos milhões. 
Por fim, o chamamento ao processo também pode proporcionar benefício ao cidadão: como o juiz deve resolver na mesma sentença a lide principal (entre autor e réu) e a secundária (entre réu e demais devedores), o direito do autor-credor é facilitado, "pois qualquer um dos codevedores, condenados na lide secundária, pode efetuar, o pagamento da dívida na ação principal"(20). Assim, nos casos em que o cidadão demande, p. ex., um Estado ou Município por medicamento adquirido, de acordo com as regras do SUS, pela União, se a União passar a integrar a lide, a satisfação da obrigação será facilitada, pois é este ente que tem mais condições de cumprir a obrigação de forma célere.

\section{Regulamentação da forma de ressarcimento entre os entes federativos}

Por fim, a derradeira opção para reduzir os prejuízos advindos dos entendimentos jurisprudenciais seria a criação de instâncias/ procedimentos administrativos para viabilizar o ressarcimento das despesas entre os entes federativos. Ocorre que, além de ser bastante improvável que os ressarcimentos ocorram de forma voluntária, como exposto anteriormente, ela apenas minimiza o problema e não tem o condão de inverter a equação, ou seja, de tornar o custo social menor que o custo privado, pois a perda de eficiência do sistema continuará a ocorrer.

Além disso, essa medida certamente gerará aumento da estrutura administrativa do Estado apenas para dar vazão aos trâmites burocráticos necessários à compensação, num cenário em que já se questiona a hipertrofia estatal e sua ineficiência.

\section{Conclusão}

Os entendimentos jurisprudenciais firmados a respeito da responsabilidade solidária dos entes federativos pelas prestações de saúde e do chamamento ao processo nas ações em que se pleiteiam tais prestações, foram proferidos sem análise profunda das origens e contornos desses institutos.

Além de partirem de premissas juridicamente equivocadas, o que permite, por si só, a revisão dos posicionamentos, as decisões proferias no RE n. 855.178/RN e Resp n. 1.203.244/SC geram consequências prejudiciais à racionalidade e funcionalidade do sistema de saúde brasileiro.

O Judiciário deve avaliar as consequências concretas das decisões que prolata, conjugando o enfoque econômico ao critério de justiça, obrigação atualmente positivada 
pela da Lei 13.655/2018. Assim, também por esse motivo, deve rever os julgados referidos, em prol da preservação da eficiência do SUS e resguardo de seus recursos financeiros e orçamentários.

Caso o Judiciário pátrio insista em manter os entendimentos firmados, a despeito da superficialidade de seus fundamentos e equívoco de premissas, vislumbra-se a possibilidade de edição de norma constitucional explicitando que a responsabilização de cada ente federativo no campo das competências comuns deve observar suas atribuições administrativas específicas. A norma editada pelo legislador constituinte derivado deve prever também que há responsabilidade conjunta na hipótese de omissão de política pública, pois o ideal perseguido pelo Federalismo Cooperativo - atuação conjunta de todas as esferas governamentais na criação de políticas públicas comuns, não pode ser relevado.

Diversas medidas podem ser adotadas para a preservação do principal valor que se intenta defender nos julgados em comento - facilitação do acesso à Justiça ao usuário do SUS —, como a especialização de varas de saúde; compilação da legislação do SUS por meio de atuação colaborativa dos atores envolvidos e, para evitar o deslocamento de pacientes para localidades munidas de varas federais, no caso de precisarem demandar a União, criação legislativa autorizando o exercício de competência federal por juízes estaduais, assim como ocorre com as demandas previdenciárias (art. 109, §3, CF/88).

\section{Referências}

(1) Timm, LB, organizador. Direito e Economia no Brasil. São Paulo: Atlas, 2ª ed.; 2014; pág. XX.

(2)Ciarlini, AL. A posição do município no Sistema Único de Saúde Reflexões a respeito da solidariedade no cumprimento das políticas públicas de assistência farmacêutica. Revista de Direito Público. V.12, n. 68, 2016, 24-39.

(3) Pereira, FF. A Federação no constitucionalismo brasileiro. [Dissertação]. São Paulo: Universidade de São Paulo; 2010. Disponível em: http://www.teses.usp.br/teses/disponiveis/2/2134/tde-07072011-090937/pt-br.php. [Acesso em 30.abr.2018].

(4) Bercovicci, G. Constituição econômica e desenvolvimento: uma leitura a partir da Constituição de 1988.São Paulo: Malheiros;2005; pág. 91. 
(5) Pereira, FF. A Federação no constitucionalismo brasileiro. [Dissertação]. São Paulo: Universidade de São Paulo; 2010; págs. 88 e 89. Disponível em: http://www.teses.usp.br/teses/disponiveis/2/2134/tde-07072011-090937/pt-br.php._[Acesso em 05.mai.2018].

(6) Abrantes, AMRG. O princípio da solidariedade e o direito econômico. Revista Prim@ Facie. V. 3, n.4, 2004, 127-139. Disponível em: http://www.periodicos.ufpb.br/ojs/index.php/primafacie/article/view/4459.[Acesso em 06.jun.2018].

(7) Bercovici, G. A descentralização de políticas públicas sociais e o federalismo cooperativo brasileiro. Revista de Direito Sanitário - USP, vol. 3, n. 1, Março de 2002. Disponível em: http://www.revistas.usp.br/rdisan/article/view/81291. [Acesso em 01.mai.2018].

(8) Bercovicci, G. Constituição econômica e desenvolvimento: uma leitura a partir da Constituição de 1988.São Paulo: Malheiros;2005.

(9) Tabosa, A. Direito Romano. Fortaleza: Imprensa Universitária; 1999; pág. 257.

(10) Di Pietro, MSZ, organizadora. Direito privado administrativo. São Paulo: Atlas; 2013; pág. 03.

(11) Beviláqua, C. Direito das obrigações. Rio de Janeiro: Editora Freitas Bastos, 4⿳a ed.; 1936.

(12) Bulos, UL. Constituição Federal anotada. São Paulo: Saraiva, 9ª ed.; 2009; pág. 564.

(13) Ciarlini, AL. A posição do município no Sistema Único de Saúde Reflexões a respeito da solidariedade no cumprimento das políticas públicas de assistência farmacêutica. Revista de Direito Público. V.12, n. 68, 2016, 24-39. Disponível em: https://www.portaldeperiodicos.idp.edu.br/direitopublico/article/view/2611. [Acesso em 14.jun.2018].

(14) Júnior, NN. Comentários ao Código de Processo Civil. São Paulo: Revista dos Tribunais; 2015; pág. 568.

(15) Castro, SHR Impacto deslocativo no orçamento público estadual em face de decisões judiciais. In.: Controle Externo - Estudos Temáticos. GUERRA, Evandro Martins; CASTRO Sebastião Helvécio Ramos de (Coord). Belo Horizonte: Forum; 2012; pág. 44.

(16) Brasil. Ministério da Saúde: Parecer n. 811/2012-AGU/CONJUR-MS/LFGF-AVA.

(17)Fiani, R. Cooperação e conflito: instituições e desenvolvimento econômico. Rio de Janeiro: Elsevier, 2011.

(18) Bezerra, FLO. Imbricações entre competência de jurisdição, legitimidade e solidariedade na tutela da saúde pública. Revista Dialética de Direito Processual. N. 81, p. 27-34, dez., 2009, pág. 33 
(19) Pereira, FF. A Federação no constitucionalismo brasileiro. [Dissertação]. São Paulo: Universidade de São Paulo; 2010. Disponível em: http://www.teses.usp.br/teses/disponiveis/2/2134/tde-07072011-090937/pt-br.php. [Acesso em 05.mai.2018].

(20) Júnior, NN. Comentários ao Código de Processo Civil. São Paulo: Revista dos Tribunais; 2015; pág. 568.

\section{Como citar este artigo:}

Almeida L. Responsabilidade solidária dos entes federativos pela obrigação de prestar serviço de saúde e vedação do chamamento ao processo: análise jurídica e econômica dos entendimentos do STF e STJ. Revista Cadernos Ibero-Americanos de Direito Sanitário. 2018 abr./jun, 7(2):124-146. 